\title{
DIFERENÇAS METODOLÓGICAS ENTRE O CADASTRO GERAL DE EMPREGADOS E DESEMPREGADOS E A PESQUISA NACIONAL POR AMOSTRA DE DOMICÍLIOS CONTÍNUA ${ }^{1,2}$
}

\section{INTRODUÇÃO}

O Brasil é reconhecido internacionalmente como um país que produz um grande volume de estatísticas sobre o tema trabalho. Entre as bases de dados atualmente disponíveis, destacamse o Cadastro Geral de Empregados e Desempregados (Caged), ${ }^{3}$ da Secretaria Especial de Previdência e Trabalho do Ministério da Economia (SEPRT/ME), e a Pesquisa Nacional por Amostra de Domicílios Contínua (PNAD Contínua), ${ }^{4}$ do Instituto Brasileiro de Geografia e Estatística (IBGE). Esta nota técnica visa especificar as principais diferenças metodológicas apresentadas entre essas duas fontes de informaçóes.

\section{PRINCIPAIS CONCEITOS E DEFINIÇÕES}

O Caged e a PNAD Contínua são bases de dados de reconhecida excelência, que possuem natureza e finalidade distintas.

\subsection{Caged}

O Caged é um registro administrativo, derivado do cumprimento de obrigação trabalhista definida pela Lei no 4.923, de 23 de dezembro de 1965, de periodicidade mensal, cujo objetivo é monitorar a evolução do mercado de trabalho formal. Os dados estatísticos do Caged ${ }^{5}$ são obtidos a partir de declaraçôes enviadas mensalmente pelos estabelecimentos, as quais dizem respeito à movimentação de empregados ao longo do mês.

1. DOI: http://dx.doi.org/10.38116/bmt70/nta3

2. Nota técnica conjunta elaborada pela SEPRT/ME e pelo IBGE.

3. Disponível em: <https://tinyurl.com/y6q8fu2h>.

4. Disponível em: <https://tinyurl.com/y3obscpy>.

5. Desde janeiro de 2020, o uso do sistema do Caged foi substituído pelo Sistema de Escrituração Digital das Obrigações Fiscais, Previdenciárias e Trabalhistas (eSocial) para parte das empresas, conforme estabelecido pela Portaria SEPRT no 1.127, de 14 de outubro de 2019. A transição do cumprimento da obrigação trabalhista para o sistema do eSocial instituiu o Novo Caged, que trata da geração das estatísticas do emprego formal por meio de informações captadas dos sistemas eSocial, Caged e Empregador Web. Nota metodológica completa em: <https://tinyurl.com/y54w9dav>. 
A declaração do Caged é obrigatória para todo estabelecimento, privado ou público, que tenha admitido, desligado ou transferido empregado com contrato de trabalho regido pela Consolidação das Leis do Trabalho (CLT). Seu universo de abrangência ${ }^{6}$ limita-se aos empregados formais celetistas, incluindo contratos de trabalho com prazo indeterminado e determinado, aprendizes, trabalhadores intermitentes, por tempo parcial e temporários (para estes últimos, a declaração é opcional). Não estão incluídos no Caged servidores da administração pública direta ou indireta, federal, estadual ou municipal, trabalhadores, autônomos e trabalhadores informais.

Os estabelecimentos têm até o dia 7 do mês subsequente para informar suas movimentaçôes no Caged. As informaçôes recebidas após esta data são processadas como declaraçôes fora do prazo e atualizam a base de dados por um período de até doze meses retroativo.

Originalmente criado para fins operacionais, o Caged constitui hoje uma das principais fontes de informaçóes estatísticas sobre o mercado de trabalho conjuntural formal, sendo amplamente utilizado por órgãos governamentais, centros de pesquisa, consultorias privadas e academia. Sua base de dados inclui informaçóes sobre os vínculos formais, informaçóes individuais dos trabalhadores, além de características dos estabelecimentos. Destaque-se que esta é a única fonte de informação sobre emprego mensal com desagregação municipal. A SEPRT/ME mantém um sistema de consulta aos dados do Caged para comprovação de vínculos dos trabalhadores e possui, desde 1987, o Programa de Disseminação das Estatísticas do Trabalho (PDET), ${ }^{7}$ que tem por objetivo divulgar informaçóes estatísticas oriundas dos registros administrativos à sociedade.

\subsection{PNAD Contínua}

A PNAD Contínua é uma pesquisa domiciliar amostral, de periodicidade trimestral, com objetivo de acompanhar as flutuações trimestrais e a evolução, no curto, médio e longo prazos, da força de trabalho, e outras informaçóes necessárias para o estudo do desenvolvimento socioeconômico do país. A pesquisa é realizada por meio de uma amostra de domicílios distribuídos em cerca de 3.500 municípios. Seus dados são obtidos a partir de entrevistas domiciliares, ${ }^{8}$ coletados por entrevistadores contratados pelo IBGE.

A PNAD Contínua capta, trimestralmente, toda a população ocupada e a população desocupada, seguindo a Resolução I (resolução sobre as estatísticas de trabalho, ocupação e subutilização da força de trabalho) adotada na 19a Conferência Internacional dos Estatísticos do Trabalho, que é realizada sob os auspícios da Organização Internacional do Trabalho (OIT). ${ }^{9}$ Abrange todos os empregados, registrados (empregados com carteira de trabalho assinada, incluindo a subgrupo dos trabalhadores domésticos com carteira de trabalho assinada, militares

6. Para mais informações sobre quem deve declarar e ser declarado no Caged, acessar o Manual de Orientação do Caged, disponível em: <https://tinyurl.com/y6q8fu2h>.

7. Disponível em: <https://tinyurl.com/y2jpgn4f>.

8. A coleta da PNAD Contínua é tradicionalmente realizada exclusivamente de forma presencial nos domicílios selecionados. Contudo, em função da situação excepcional da pandemia da Covid-19, a coleta da pesquisa está sendo feita por telefone.

9. Disponível em: <https://bit.ly/2HgZNbs>. 
e funcionários públicos estatutários) e não registrados (empregados sem carteira de trabalho assinada), e os trabalhadores independentes (conta-própria, empregadores e trabalhadores familiares auxiliares). Capta, ainda, as pessoas não ocupadas em procura efetiva por trabalho (pessoas desocupadas), abarcando, assim, toda a força de trabalho do país.

A amostra da PNAD Contínua foi planejada para permitir produzir resultados para Brasil, Grandes Regióes, Unidades da Federação (UFs), municípios das capitais, regióes metropolitanas (RMs) que contêm os municípios das capitais e Região Integrada de Desenvolvimento da Grande Teresina.

Os indicadores da PNAD Contínua para o acompanhamento da evolução de curto prazo da força de trabalho são divulgados:

- trimestralmente: em sua grande maioria, para todos os níveis geográficos para os quais a pesquisa foi planejada para permitir produzir resultados; e

- mensalmente: para um conjunto selecionado de indicadores e somente para o nível geográfico Brasil. Os indicadores produzidos mensalmente utilizam as informações dos últimos três meses consecutivos da pesquisa. Assim, esses indicadores mensais não refletem a situação de cada mês, mas do trimestre móvel que finaliza a cada mês.

Além disso, a PNAD Contínua também produz resultados anuais para os demais temas permanentes da pesquisa e indicadores complementares relacionados à força de trabalho. Pode, também, vir a produzir resultados para outros temas ou tópicos com periodicidade variável.

\section{PRINCIPAIS DIFERENÇAS METODOLÓGICAS}

O quadro 1 sistematiza as principais diferenças metodológicas entre o Caged e a PNAD Contínua.

QUADRO 1

Diferenças metodológicas entre o Caged e a PNAD Contínua

\begin{tabular}{|c|c|c|}
\hline & Caged & PNAD Contínua \\
\hline Unidade descrita & Vínculo de trabalho celetista. & Pessoa. \\
\hline Natureza do levantamento & Registro administrativo. & Pesquisa por amostra probabilística de domicílios. \\
\hline Informante & Estabelecimento (empresa). & Morador do domicílio. \\
\hline Nível de divulgação das informações & $\begin{array}{l}\text { Brasil, Grandes Regiões, UFs, mesorregiões, } \\
\text { microrregiões, RMs e municípios. }\end{array}$ & $\begin{array}{l}\text { Brasil, Grandes Regiões, UFs, municípios das } \\
\text { capitais, RMs que contêm municípios das capi- } \\
\text { tais e Região Integrada de Desenvolvimento da } \\
\text { Grande Teresina. }\end{array}$ \\
\hline Cobertura & $\begin{array}{l}\text { Vínculos celetistas que tiveram movimen- } \\
\text { tação (admissão ou desligamento) no mês } \\
\text { de referência. }\end{array}$ & $\begin{array}{l}\text { Pessoas de } 14 \text { anos ou mais de idade na con- } \\
\text { dição de: } \\
\text { ocupadas: trabalhadores com e sem carteira } \\
\text { de trabalho assinada (setor privado e público), } \\
\text { trabalhadores domésticos, militares e funcionários } \\
\text { públicos estatutários, empregadores, trabalhadores } \\
\text { por conta-própria (com e sem Cadastro Nacional } \\
\text { da Pessoa Jurídica - CNPJ) e trabalhadores } \\
\text { familiares auxiliares; } \\
\text { desocupadas; e } \\
\text { fora da força de trabalho. }\end{array}$ \\
\hline
\end{tabular}

(Continua) 


\begin{tabular}{|c|c|c|}
\hline & Caged & PNAD Contínua \\
\hline $\begin{array}{l}\text { Abrangência geográfica do } \\
\text { levantamento }\end{array}$ & Nacional. & Nacional. \\
\hline Referência geográfica & $\begin{array}{l}\text { Endereço do estabelecimento (local de } \\
\text { trabalho). }\end{array}$ & Domicílios particulares permanentes. \\
\hline $\begin{array}{l}\text { Período de referência da } \\
\text { informação }\end{array}$ & Mês de referência da movimentação. & $\begin{array}{l}\text { Semana de referência para ocupação e período } \\
\text { de referência de trinta dias para a desocupação. }\end{array}$ \\
\hline $\begin{array}{l}\text { Período de referência da divul- } \\
\text { gação dos resultados }\end{array}$ & Mês seguinte ao de referência. & $\begin{array}{l}\text { Trimestral: mês seguinte ao trimestre civil encerrado. } \\
\text { Mensal: mês seguinte ao trimestre móvel encerrado. }\end{array}$ \\
\hline
\end{tabular}

Elaboração dos autores.

\section{CONCLUSÃO}

Tendo em vista as diferenças metodológicas apresentadas no quadro 1, bem como as diferenças de natureza e finalidade entre o Caged e a PNAD Contínua, não é recomendável a comparação dos resultados obtidos por estas duas fontes de informação.

\section{BIBLIOGRAFIA COMPLEMENTAR}

ALMEIDA, M. E. et al. Comparando bases de dados: o caso do Cadastro Geral de Empregados e Desempregados (Caged) e da Pesquisa Nacional por Amostra de Domicílios contínua (PNAD contínua). Mercado de trabalho: conjuntura e análise, n. 65, out. 2018.

BRASIL. Ministério da Economia. Secretaria Especial de Previdência e Trabalho. Substituiçáo da captaçáo dos dados do Caged pelo eSocial. Brasília, 27 maio 2020. (Nota técnica). Disponível em: <https://tinyurl.com/y54w9dav>.

COURSEUIL, C. H. L. et al. Mais sobre as diferenças na evolução do emprego formal na PNAD contínua e no CAGED. Mercado de trabalho: conjuntura e análise, n. 67, out. 2019. IBGE - INSTITUTO BRASILEIRO DE GEOGRAFIA E ESTATÍSTICA. Pesquisa Nacional por Amostra de Domicílios Contínua. Rio de Janeiro: IBGE, 2020. (Nota técnica, versão 1.8).

IBGE - INSTITUTO BRASILEIRO DE GEOGRAFIA E ESTATÍSTICA; BRASIL. Ministério do Trabalho e Emprego. Caged e PME: diferenças metodológicas e possibilidades de comparação. 25 out. 2004. (Nota Técnica IBGE-MTE). 